\title{
Terlipressin protects intestinal epithelial cells against oxygen-glucose deprivation/re-oxygenation injury via the phosphatidylinositol 3-kinase pathway
}

\author{
ZI-MENG LIU $^{1 *}$, XU-YU ZHANG ${ }^{2 *}$, JUAN CHEN $^{1}$, JIAN-TONG SHEN $^{2}$, ZHI-YI JIANG $^{1}$ and XIANG-DONG GUAN ${ }^{1}$ \\ ${ }^{1}$ Surgical Intensive Care Unit; ${ }^{2}$ Department of Anesthesiology, \\ The First Affiliated Hospital, Sun Yat-sen University, Guangzhou, Guangdong 510080, P.R. China
}

Received December 31, 2015; Accepted February 1, 2017

DOI: $10.3892 /$ etm.2017.4502

\begin{abstract}
Intestinal ischemia/reperfusion (I/R) injury is associated with a high morbidity and mortality. Vasopressin is administered to critically ill patients with potential intestinal I/R. However, the impacts of vasopressin on intestinal epithelia under ischemic/anoxic conditions remain unclear. The aim of the present study was to evaluate the effects of terlipressin, a highly selective vasopressin V1 receptor agonist, on oxygen and glucose deprivation/re-oxygenation (OGD/R)-induced damage in intestinal epithelial cells (IEC-6). IEC-6 cells were subjected to OGD for $4 \mathrm{~h}$, followed by $4 \mathrm{~h}$ re-oxygenation. Terlipressin was incubated with cells for $4 \mathrm{~h}$ following OGD. Following OGD/R, IEC-6 cell viability, proliferation and apoptosis, as well as cell cycle dynamics, were assessed and the levels of tumor necrosis factor (TNF)- $\alpha$ and 15-F2t-isoprostane in the culture medium were measured. In addition, wortmannin, a specific phosphatidylinositol 3-kinase (PI3K) inhibitor, was administrated to investigate the mechanism of terlipressin action. The results demonstrated that IEC-6 cell viability and proliferation decreased, and cell apoptosis increased, following OGD/R. However, IEC-6 cell cycle dynamics did not significantly change $4 \mathrm{~h}$ after OGD. Incubation with $25 \mathrm{nM}$ terlipressin significantly improved cell viability, proliferation and apoptosis. Furthermore, terlipressin inhibited the secretion of TNF- $\alpha$ and 15-F2t-isoprostane from IEC-6 cells following OGD/R. The aforementioned effects of terlipressin were completely abolished following the application of $2 \mu \mathrm{M}$ wortmannin. Therefore, the current study
\end{abstract}

Correspondence to: Professor Xiang-Dong Guan, Surgical Intensive Care Unit, The First Affiliated Hospital, Sun Yat-sen University, 58 Zhongshan 2nd Road, Guangzhou, Guangdong 510080, P.R. China

E-mail: guangxiangdong1962@163.com

*Contributed equally

Key words: ischemia-reperfusion injury, intestinal epithelial cell, terlipressin, vasopressin, wortmannin demonstrated that terlipressin administration following OGD attenuates OGD/R-induced cell damage via the PI3K signaling pathway. These results may help physicians to better understand and more effectively use terlipressin in a clinical setting.

\section{Introduction}

Intestinal ischemia/reperfusion (I/R) injury usually occurs following acute mesenteric ischemia, severe trauma or burns, hemorrhagic or septic shock, and major surgical procedures (1). Intestinal I/R causes excessive inflammation, oxidative response and cell apoptosis, and subsequently leads to the disruption of the intestinal barrier and distant organ damage (1). The development of intestinal I/R is associated with multiple organ dysfunction syndrome and a high probability of mortality $(2,3)$. Indeed, a recent multicenter study determined that the mortality rate from acute mesenteric ischemia in intensive care units (ICU) was as high as $58 \%$ (4). In clinical settings, vasopressors including norepinephrine and dobutamine are essential to maintain blood pressure and systemic perfusion in critically ill patients with intestinal I/R injury.

Vasopressin is generally used for cardiovascular support in the ICU (5) and is recommended for the treatment of severe sepsis and septic shock (6). However, it remains unclear whether vasopressin aggravates intestinal I/R injury. Previous studies have suggested that vasopressin decreases intestinal mucosal perfusion and diminishes the beneficial effect of norepinephrine due to its potent vasoconstriction (7-9). This suggests that the use of vasopressin may further deteriorate intestinal mucosal ischemia in critically ill patients with intestinal I/R. However, other studies have indicated that vasopressin does not compromise gut mucosal microcirculation and oxygen supply $(10,11)$. To the best of our knowledge, there have been no studies investigating the effects of vasopressin on intestinal mucosal epithelial cells, the key component of the intestinal barrier, under I/R conditions. Thus, it is of clinical relevance to clarify the effect of vasopressin and its analogue on intestinal epithelial tissues in patients at risk of intestinal ischemia.

Performing oxygen and glucose deprivation and re-oxygenation $(\mathrm{OGD} / \mathrm{R})$ in vitro is a popular method to simulate organic $\mathrm{I} / \mathrm{R}$ in vivo. Therefore, the present study was designed to assess 
the effects of terlipressin, a highly selective vasopressin V1 receptor agonist, on the production of inflammatory and oxidative cytokines in rat intestinal epithelial cells (IEC-6), and on cell viability and proliferation in the OGD/R model.

\section{Materials and methods}

IEC-6 cell culture. Rat IEC-6 intestinal epithelial cells (CRL-1592; passage 16-20; American Type Culture Collection, Manassas, VA, USA) were cultured as previously described (12). Briefly, IEC-6 cells were cultured in Dulbecco's modified Eagle's medium (DMEM) containing $4.5 \mathrm{~g} / \mathrm{l} \mathrm{D}$-glucose, $10 \% \mathrm{v} / \mathrm{v}$ fetal bovine serum (all from Sigma-Aldrich; Merck KGaA, Darmstadt, Germany) and $1 \%$ penicillin/streptomycin (Invitrogen; Thermo Fisher Scientific, Inc., Waltham, MA, USA) and maintained under standard cell culture conditions of $37^{\circ} \mathrm{C}, 5 \% \mathrm{CO}_{2}$ and $21 \% \mathrm{O}_{2}$ for $24 \mathrm{~h}$.

$O G D / R$. OGD intervention was conducted as previously described (12). Briefly, after the IEC-6 cells were grown under normal conditions up to $80 \%$ confluence, the DMEM was replenished with D-Hanks buffer (Sigma-Aldrich; Merck $\mathrm{KGaA}$ ) and cells were incubated in a modular incubator chamber filled with a $95 \% \mathrm{~N}_{2}$ and $5 \% \mathrm{CO}_{2}$ gas mixture for $4 \mathrm{~h}$ at $37^{\circ} \mathrm{C}$. Following completion of OGD, medium was changed back to normoxic medium and the cells were incubated under normal conditions for $4 \mathrm{~h}$ (re-oxygenation).

Study groups and experimental protocol. IEC-6 cells were randomly assigned to receive different concentrations (1, 5, 25 or $125 \mathrm{nM}$ ) terlipressin (Hybio Pharmaceutical Co., Ltd., Shenzhen, China) following OGD, and then an appropriate concentration of terlipressin $(25 \mathrm{nM})$ was selected according to the results of the cell viability test. Subsequently, cells were incubated with the chosen concentration of terlipressin and/or phosphatidylinositol 3-kinase (PI3K) inhibitor (Wortmannin; Beyotime Institute of Biotechnology, Haimen, China). Cells were randomly assigned to one of 5 groups (5 samples per group) as follows: i) Sham group: IEC-6 cells were incubated in normoxic medium for $8 \mathrm{~h}$; ii) OGD/R group: IEC-6 cells were incubated for $4 \mathrm{~h}$ OGD followed by $4 \mathrm{~h}$ re-oxygenation; iii) terlipressin group: Following $4 \mathrm{~h}$ OGD, IEC- 6 cells were incubated with $25 \mathrm{nM}$ terlipressin for $4 \mathrm{~h}$; iv) wortmannin group: Following $4 \mathrm{~h}$ OGD, IEC-6 cells were incubated with $2 \mu \mathrm{M}$ wortmannin, a specific PI3K inhibitor, for $4 \mathrm{~h}$; or v) T+W group: $2 \mu \mathrm{M}$ wortmannin and $25 \mathrm{nM}$ terlipressin were simultaneously administrated at the beginning of re-oxygenation. The detailed experimental protocol is presented in Fig. 1.

Cell viability assay. IEC-6 cells were seeded into 96-well plates $\left(1 \times 10^{5}\right.$ cells/well) and incubated overnight at $37^{\circ} \mathrm{C}$ in $5 \% \mathrm{CO}_{2}$. Cells were then treated according to the aforementioned experimental protocol, with a sham cell group as a control. An MTT assay was used to determine cell viability as previously described (12). Briefly, MTT (3-(4,5-dimethylthiazol-2-yl)-2,5-diphenyl tetrazoliumbromide; $5 \mathrm{mg} / \mathrm{ml}$ in phosphate-buffered saline) reagent (Sigma-Aldrich; Merck $\mathrm{KGaA}$ ) was added to each well and incubated for $4 \mathrm{~h}$ at $37^{\circ} \mathrm{C}$. Medium was then replaced with $150 \mu 1$ dimethyl sulfoxide.
Optical density (OD) was recorded using a microplate reader at the wavelength of $490 \mathrm{~nm}$. Cell viability was expressed as a percentage of the Sham.

Cell cycle analysis. Cell cycle distribution was measured by a flow cytometry assay with propidium iodide (PI) DNA staining. Briefly, IEC-6 cells were seeded into 96-well plates $\left(1 \times 10^{5}\right.$ cells/well) and treated according to the aforementioned experimental protocol, with a sham cell group as a control. Cells were harvested and digested with $0.25 \%$ trypsin solution without EDTA (Sigma-Aldrich; Merck KGaA) for $15 \mathrm{~min}$ at $37^{\circ} \mathrm{C}$, then isolated by centrifugation at $200 \mathrm{x} \mathrm{g}$ for 2 min at $4^{\circ} \mathrm{C}$ and washed twice with cold phosphate-buffered saline (PBS). Following $100 \mu \mathrm{m}$ mesh sieve screening; the cell suspension was fixed with $75 \%$ ethanol at $4^{\circ} \mathrm{C}$ for $24 \mathrm{~h}$. Cells were harvested by centrifugation at $200 \mathrm{x} \mathrm{g}$ for $10 \mathrm{~min}$ at $4^{\circ} \mathrm{C}$ and two washes in cold PBS, followed by centrifugation at $200 \mathrm{x}$ g for $5 \mathrm{~min}$ at $4^{\circ} \mathrm{C}$ and cell collection by discarding of the supernatant. The cell suspension was then treated with $100 \mu 1$ RNase (0.01 mol/1, Sigma-Aldrich; Merck $\mathrm{KGaA}$ ) at $37^{\circ} \mathrm{C}$ for $30 \mathrm{~min}$ in a water bath, followed by treatment with PI staining solution $(0.5 \mathrm{mg} / \mathrm{l}$; Beyotime Institute of Biotechnology). Following $30 \mathrm{~min}$ of gentle mixing, cells were stored at $4^{\circ} \mathrm{C}$ in the dark for $30 \mathrm{~min}$, then analyzed with a FACSCalibur ${ }^{\mathrm{TM}}$ Cell Analyzer (BD Biosciences, CA, USA). Red fluorescence at $488 \mathrm{~nm}$ was recorded using a microplate reader (Thermo Fisher Scientific, Inc.) and results were analyzed using Flowjo 7.6.3 software (Tree Star, Inc., OR, USA).

Cell proliferation assay. IEC-6 cell proliferation was measured using a cell counting kit-8 (CCK-8, Beyotime Institute of Biotechnology). At baseline (the start of experiment), and 24,48 and $72 \mathrm{~h}$ after baseline, $5 \times 10^{3}$ cells/well were propagated in a $5 \% \mathrm{CO}_{2}$ atmosphere at $37^{\circ} \mathrm{C}$. Then, $\mathrm{CCK}-8$ reagent was applied to the DMEM, incubated for $1 \mathrm{~h}$ and absorbance at $450 \mathrm{~nm}$ was measured using a multiwell spectrophotometer.

Apoptosis assay. IEC-6 cell apoptosis was measured by flow cytometry, following a previously described procedure (12). Cells were washed twice with cold PBS and stained with fluorescein isothiocyanate (FITC) Annexin V and PI using the Annexin V-FITC Apoptosis Detection kit I (BD Biosciences) for $15 \mathrm{~min}$ at room temperature in the dark. Stained cells were analyzed using flow cytometry within $1 \mathrm{~h}$. The Annexin $\mathrm{V}^{+} / \mathrm{PI}^{-}$and Annexin $\mathrm{V}^{+} / \mathrm{PI}^{+}$cell populations were considered to represent apoptotic cells. The apoptosis index was calculated as: (Apoptotic cells/total cells) x100.

Tumor necrosis factor (TNF)- $\alpha$ and isoprostant assay. Following re-oxygenation, the culture medium was centrifuged at $600 \mathrm{x} \mathrm{g}$ for $5 \mathrm{~min}$ at $4^{\circ} \mathrm{C}$, and the supernatant was collected. 15-F2t-isoprostane is a representative index of oxidative stress-induced lipid peroxidation (13). The concentrations of TNF- $\alpha$ and 15-F2t-isoprostane in the supernatant were determined using commercial kits (TNF- $\alpha$ : RTA00; R\&D System, Inc., MN, USA and 15-F2t-isoprostane: 500431; Cayman Chemical Company, MI, USA), according to the manufacturer's procedure, as described previously $(14,15)$. 


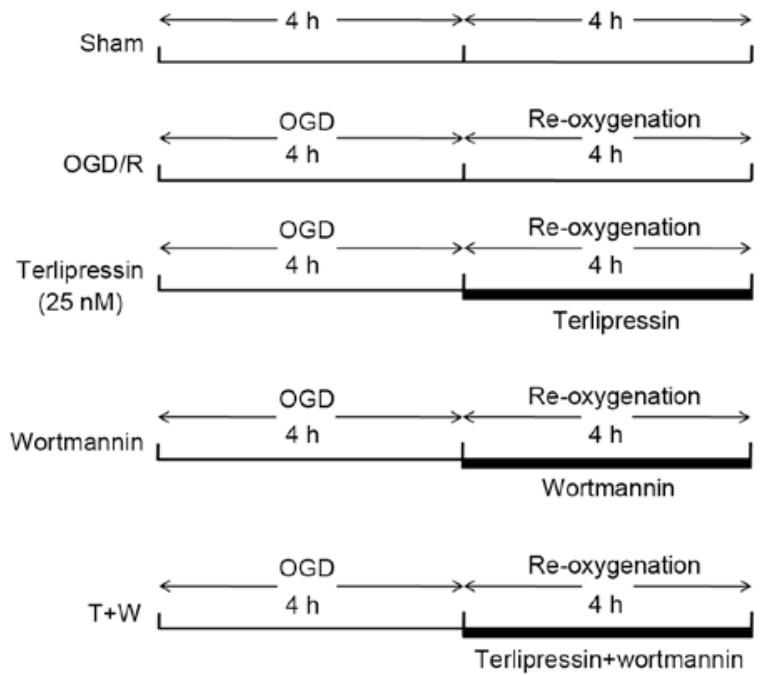

Figure 1. Experimental protocol. Sham, IEC-6 cells were incubated in normoxic medium for $8 \mathrm{~h}$; OGD/R, IEC- 6 cells were incubated for $4 \mathrm{~h}$ in OGD medium followed by $4 \mathrm{~h}$ re-oxygenation; Terlipressin, $25 \mathrm{nM}$ terlipressin was administrated following OGD; Wortmannin, $2 \mu \mathrm{M}$ wortmannin was administrated following OGD; $\mathrm{T}+\mathrm{W}$, terlipressin and wortmannin were simultaneously administered following re-oxygenation. OGD/R, oxygen and glucose deprivation/re-oxygenation; $\mathrm{T}$, terlipressin; W, wortmannin.

Statistical analysis. Results were analyzed using SPSS 15.0 software (SPSS Inc, Chicago, IL, USA). Data were expressed as mean \pm standard deviation. Data concerning cell proliferation were analyzed by two-way analysis of variance (ANOVA) with repeated measures. Other data were analyzed by one-way ANOVA with Tukey's post-test. $\mathrm{P}<0.05$ was considered to indicate a statistically significant difference.

\section{Results}

Effect of terlipressin on IEC-6 cell viability following OGD/R . As presented in Fig. 2A, cell viability significantly decreased in the $\mathrm{OGD} / \mathrm{R}$ group $(\mathrm{P}<0.01$ vs. Sham). Incubation with $25 \mathrm{nM}$ and $125 \mathrm{nM}$ terlipressin increased cell viability (both $\mathrm{P}<0.01$ vs. OGD/R), and cell viability in $125 \mathrm{nM}$ group was similar to that in $25 \mathrm{nM}$ group ( $\mathrm{P}=0.756)$. Therefore, $25 \mathrm{nM}$ terlipressin was selected to use in subsequent experiments. As depicted in Fig. 2B, cell viability significantly decreased in the $\mathrm{OGD} / \mathrm{R}$, Wortmannin and $\mathrm{T}+\mathrm{W}$ groups (all $\mathrm{P}<0.01 \mathrm{vs}$. Sham). In addition, cell viability in the terlipressin group was significantly higher than that in the OGD/R, Wortmannin and $\mathrm{T}+\mathrm{W}$ groups (all $\mathrm{P}<0.01$ ), and was significantly lower than that in the Sham group $(\mathrm{P}<0.01)$.

Effect of terlipressin on IEC-6 cell cycle dynamics following $O G D / R$. As shown in Fig. 3, OGD/R intervention did not significantly alter cell cycle dynamics $4 \mathrm{~h}$ after re-oxygenation (all $\mathrm{P}>0.05$ vs. Sham). Furthermore, terlipressin did not significantly influence the percentage of IEC-6 cells in G1 phase and in S-phase (all $\mathrm{P}>0.05$ vs. OGD/R). Wortmannin and $\mathrm{T}+\mathrm{W}$ did not significantly alter the percentage of IEC- 6 cells in different phases of the cell cycle ( $\mathrm{P}>0.05$; Fig. 3).

Effect of terlipressin on IEC-6 cell proliferation following $O G D / R$. As indicated in Fig. 4, $24 \mathrm{~h}$ following the beginning
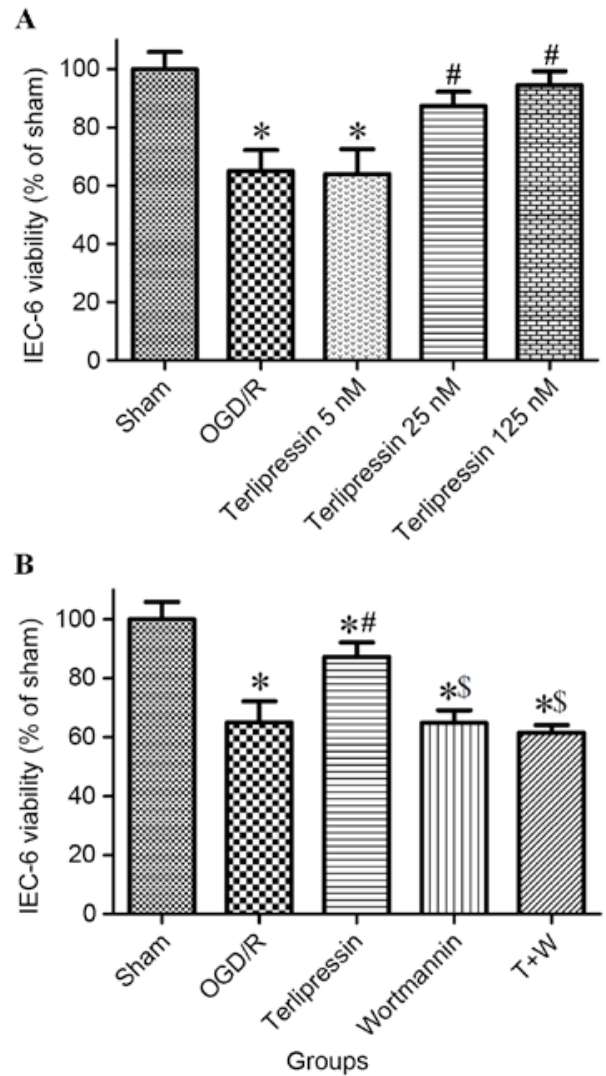

Figure 2. Changes in IEC-6 cell viability following OGD/R. (A) Effect of different concentrations of terlipressin on IEC-6 cell viability following $\mathrm{OGD} / \mathrm{R}$. (B) Impact of $2 \mu \mathrm{M}$ wortamannin on the improvement of cell viability conferred by $25 \mathrm{nM}$ terlipressin. Data were expressed as mean \pm standard deviation. $n=5$. Results were compared by one-way analysis of variance with a Tukey's post-test. ${ }^{*} \mathrm{P}<0.01$ vs. the Sham group; ${ }^{\#} \mathrm{P}<0.01$ vs. the OGD/R group; ${ }^{\$} \mathrm{P}<0.01$ vs. the Terlipressin group. OGD/R, oxygen and glucose deprivation/re-oxygenation; T, terlipressin; W, wortmannin.

of experiment (baseline), the OD value in the OGD/R group was similar to that in the Sham group $(\mathrm{P}=0.997)$. OD values at 48 and $72 \mathrm{~h}$ were significantly lower in the OGD/R group compared with the control (both $\mathrm{P}<0.01$ vs. Sham). However, incubation with $25 \mathrm{nM}$ terlipressin significantly increased the $\mathrm{OD}$ values at 48 and $72 \mathrm{~h}(\mathrm{P}=0.034$ and $\mathrm{P}=0.035$ vs. $\mathrm{OGD} / \mathrm{R}$, respectively).

Effect of terlipressin on IEC-6 cell apoptosis following $O G D / R$. Apoptosis in IEC-6 cells was measured following OGD/R (Fig. 5). The flow cytometry gating strategy is depicted in Fig. 5A and representative histograms of each group are presented in Fig. 5B. The apoptosis index in the OGD/R group was significantly higher than that in the Sham group $(\mathrm{P}<0.01$; Fig. $5 \mathrm{C})$. However, terlipressin attenuated OGD/R-induced cell apoptosis $(\mathrm{P}<0.01$ vs. OGD/R; Fig. 5C).

Effect of terlipressin on the production of TNF- $\alpha$ and isoprostane following $O G D / R$. TNF- $\alpha$ and 15-F2t-isoprostane levels increased following OGD/R (both $\mathrm{P}<0.01$ vs. Sham; Fig. 6). Furthermore, terlipressin significantly inhibited the production of TNF- $\alpha$ and 15-F2t-isoprostane from IEC-6 cells (both $\mathrm{P}<0.01$ vs. OGD/R; Fig. 6). 

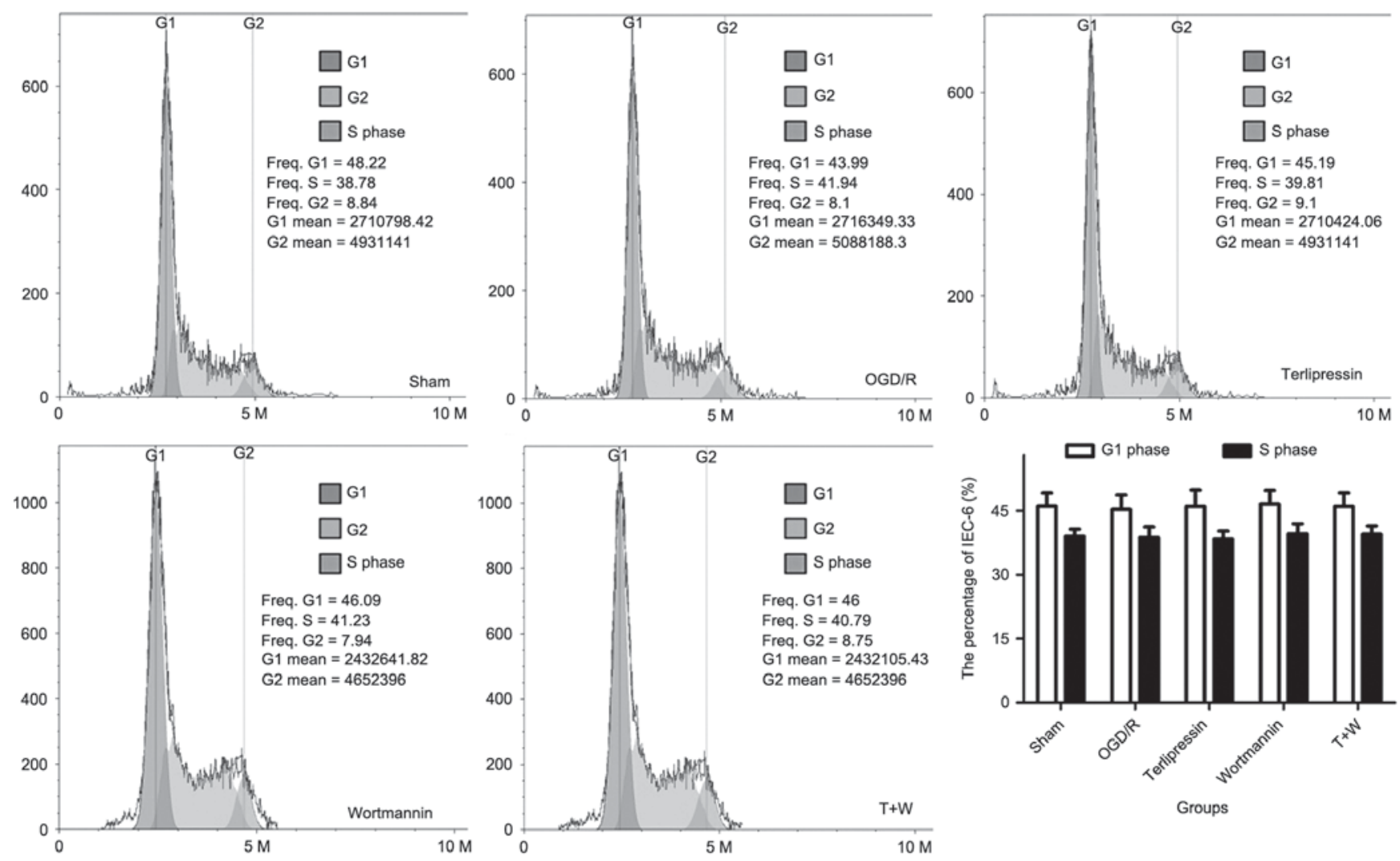

Figure 3. Changes in IEC-6 cell cycle dynamics following OGD/R. Representative flow cytometry cell cycle profiles in each group, and analysis of the percentage of IEC- 6 cells in G1 and S phase were shown, respectively. Data are expressed as the mean \pm standard deviation, $n=5$. Results were compared by one-way analysis of variance with a Tukey's post-test. OGD/R, oxygen and glucose deprivation/re-oxygenation; T, terlipressin; W, wortmannin.

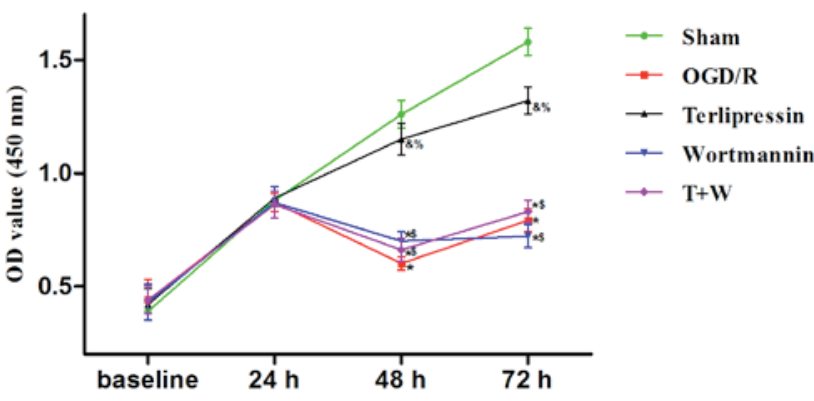

Figure 4. Changes in IEC-6 cell proliferation following OGD/R. IEC-6 cell proliferation (OD value) assessed by cell counting kit-8 assay in each group was shown. Data is expressed as the mean \pm standard deviation, $\mathrm{n}=5$. Results were compared by two-way analysis of variance with repeated measures. ${ }^{*} \mathrm{P}<0.01$ vs. the Sham group; ${ }^{\&} \mathrm{P}<0.05$ vs. the Sham group; ${ }^{\%} \mathrm{P}<0.05$ vs. the OGD/R group; ${ }^{\$} \mathrm{P}<0.01$ vs. the Terlipressin group. OGD/R, oxygen and glucose deprivation/re-oxygenation; T: terlipressin, W, wortmannin; OD, optical density.

Effect of wortmannin on terlipressin-induced cell protection following $O G D / R$. Wortmannin alone (Wortmannin group) produced no significant impacts on the aforementioned variables compared with the OGD/R group (all P $>0.05$; Figs. 2-6). In the $\mathrm{T}+\mathrm{W}$ group, wortmannin completely attenuated the effects of terlipressin on cell viability, proliferation and apoptosis (Figs. 2B, 4 and 5C). Moreover, the increased secretion of TNF- $\alpha$ and 15-F2t-isoprostane induced by terlipressin was also abolished by wortmannin (Fig. 6).

\section{Discussion}

In clinical settings, intestinal I/R injury is a serious condition and usually occurs prior to treatment with vasopressors. Therefore, in the present study, terlipressin was administrated following OGD to assess its effects on intestinal epithelial cells. The results of the current study demonstrated that terlipressin decreased the production of TNF- $\alpha$ and isoprostane in IEC- 6 cells and improved cellular viability and proliferation, and decreased rates of apoptosis during OGD/R. Furthermore, the aforementioned protective effects of terlipressin were abolished by the specific PI3K inhibitor wortmannin.

Previous studies have indicated that vasopressin reduces neuronal death and apoptosis via the vasopressin V1a receptor $(16,17)$. Similarly, Higashiyama et al (18) determined that arginine vasopressin inhibits the serum deprivation-induced apoptosis of glomerular mesangial cells by activating the V1a receptor. It has been demonstrated that in animals, apoptosis is the predominant mechanism of mucosal epithelial cell death during destruction of the intestinal epithelial barrier induced by intestinal I/R injury (19). Furthermore, a recent study performed by the current authors indicated that OGD/R significantly enhanced IEC-6 apoptosis in vitro and that remifentanil, a commonly used analgesic in general anesthesia, inhibited cell apoptosis and improved cell viability (12). To date however, no studies have investigated the effects of vasopressin on epithelial cell damage conferred by OGD/R. To the best of our knowledge, the current study is the first to demonstrate that terlipressin, an analogue of vasopressin, not only promoted IEC-6 viability but 
A
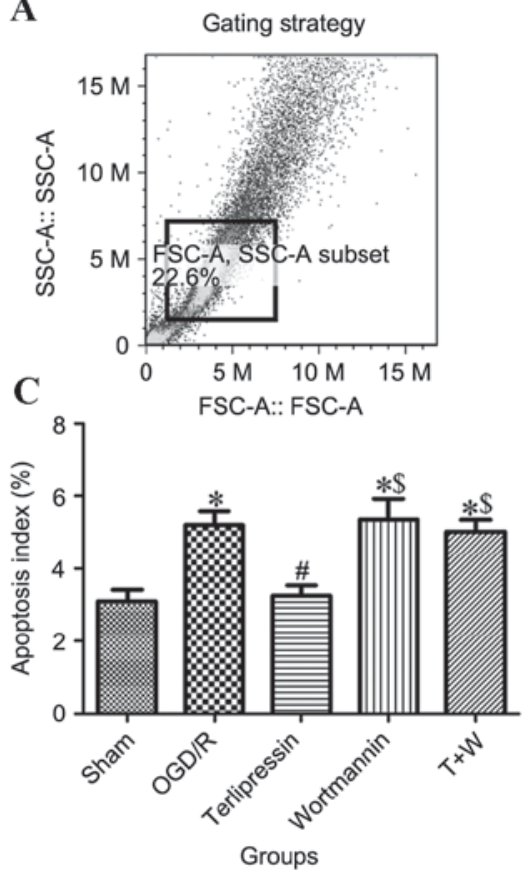

B
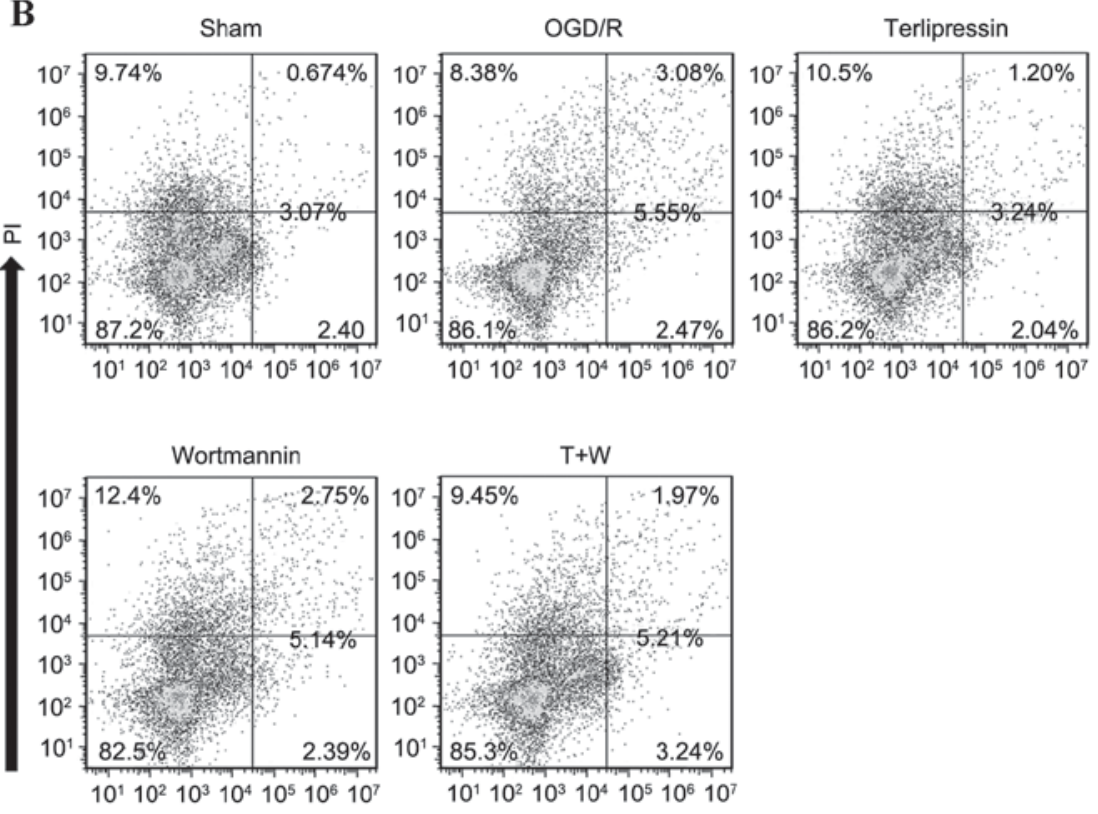

Annexin

Figure 5. Changes in IEC-6 cell apoptosis following OGD/R. IEC-6 cell apoptosis in each group was assessed using flow cytometry. (A) The gating strategy for flow cytometry is presented. (B) Representative flow cytometric profiles are presented. The cell populations of annexin $\mathrm{V}^{+} / \mathrm{PI}^{+}$and annexin $\mathrm{V}^{+} / \mathrm{PI}^{-}$were considered to represent apoptotic cells. (C) Analysis of the apoptotic index of IEC-6 cells in each group is presented. Apoptotic index was calculated as (apoptotic cells/total cells) $x 100$. Data were expressed as mean \pm standard deviation, $n=5$. Results were compared by one-way analysis of variance with Tukey's post-test. "P $<0.01$ vs. the Sham group; ${ }^{*} \mathrm{P}<0.01$ vs. the OGD/R group; ${ }^{\mathrm{P}} \mathrm{P}<0.01$ vs. the Terlipressin group. OGD/R, oxygen and glucose deprivation/re-oxygenation; $\mathrm{PI}$, propidium iodide; $\mathrm{T}$, terlipressin; $\mathrm{W}$, wortmannin.
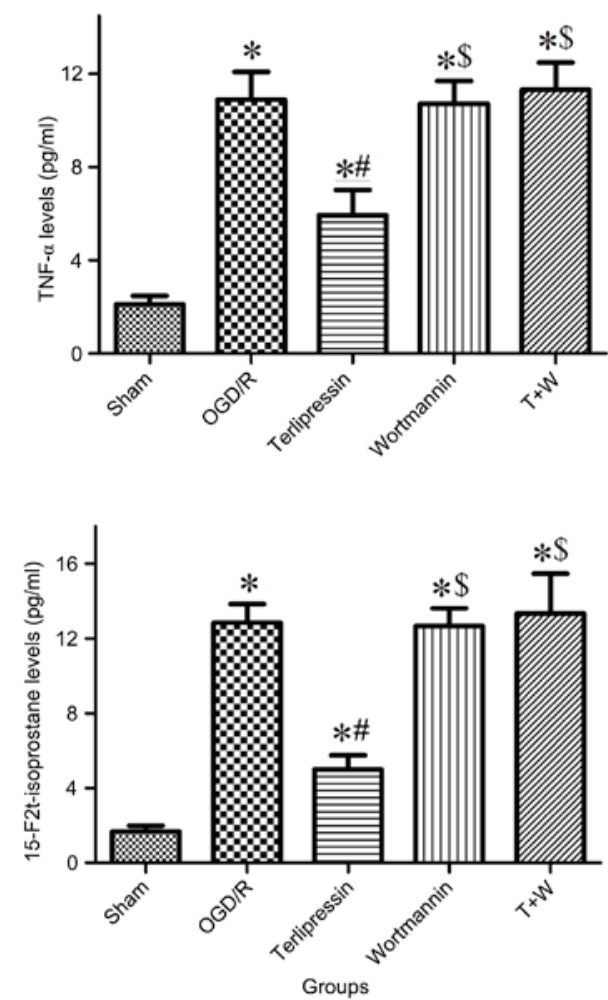

Figure 6. Changes in TNF- $\alpha$ and isoprostane production from IEC-6 cell following OGD/R. TNF- $\alpha$ and 15-F2t-isoprostane levels in the culture medium were assessed by immunoassay. Data are presented as mean \pm standard deviation, $\mathrm{n}=5$. Results were compared by one-way analysis of variance with Tukey's post-test. ${ }^{*} \mathrm{P}<0.01$ vs. the Sham group; ${ }^{\#} \mathrm{P}<0.01$ vs. the $\mathrm{OGD} / \mathrm{R}$ group; ${ }^{\$} \mathrm{P}<0.01$ vs. the Terlipressin group. OGD/R, oxygen and glucose deprivation/re-oxygenation; T, terlipressin; W, wortmannin; TNF- $\alpha$, tumor necrosis factor $\alpha$. also decreased cellular apoptosis during OGD/R (Figs. 2 and 5), indicating that terlipressin management in vivo may provide direct protection for intestinal epithelial cells against I/R injury. Interestingly, incubation with terlipressin did not affect cell cycle and cell proliferation in the early period $(<48 \mathrm{~h})$ following re-oxygenation (Fig. 3) but significantly increased IEC-6 proliferation 48 and $72 \mathrm{~h}$ following OGD (Fig. 4). This delayed increase of cell proliferation induced by terlipressin may promote intestinal epithelial repair following intestinal I/R injury.

A previous study by the current authors indicated that overactivation of inflammatory response and oxidative stress was involved in the pathogenesis of intestinal I/R injury (15). Uncontrolled production of reactive oxygen species and inflammatory cytokines, including TNF- $\alpha$ and interleukin 1 , is closely associated with the disruption of intestinal epithelia (20-21). A number of studies have determined that $\mathrm{OGD} / \mathrm{R}$ increases the release of inflammatory cytokines or oxidative molecules in neural, renal tubular and vascular endothelial cells (22-25). The results of the present study demonstrated that $\mathrm{OGD} / \mathrm{R}$ increased secretion of TNF- $\alpha$ and isoprostane from intestinal epithelial cells (Fig. 6). Ferrier et al (26) suggested that vasopressin increased TNF- $\alpha$ and myeloperoxidase levels through the $\mathrm{V} 1 \mathrm{~b}$ receptor in gut inflammatory disease. However, in septic animals, several studies have demonstrated that vasopressin may attenuate tissue inflammation and oxidative stress by activating the V1a receptor (27-29). Data from the current study indicate that terlipressin exerts anti-inflammatory and anti-oxidative effects during OGD/R attack (Fig. 6), suggesting that terlipressin may principally act on the V1a receptor of IEC-6 cells. Further 
investigations are required to determine the definite impacts of terlipressin, in vivo, on intestinal inflammation and oxidation during intestinal I/R insult.

Previous studies have indicated that vasopressin V1 receptor agonists deliver their effects through the PI3K signaling pathway $(16,30)$. V1 receptors couple to Gq protein and $\mathrm{Gq}$ subsequently activates phospholipase C and PI3K (31). Notably, the PI3K pathway is involved in inflammation, oxidation and cell apoptosis under ischemic conditions (32-34). Therefore, a PI3K specific inhibitor, wortmannin, was used to explore the potential signaling pathway of terlipressin in this study. The results indicated that the protective effects of terlipressin were completely abolished by wortmannin (Figs. 2B and 4-6), indicating that terlipressin reduced OGD-induced IEC- 6 cell damage via the PI3K pathway in vitro.

The current study had several limitations. Firstly, the effects of terlipressin on IEC-6 cells were investigated using an in vitro $\mathrm{OGD} / \mathrm{R}$ model. Further analyses should be conducted to clarify the effects and mechanisms of telipressin on intestinal I/R injury in animals and in patients. Secondly, although terlipressin has a high binding affinity to V1 receptor agonist, a specific V1 receptor antagonist should be applied to verify that IEC- 6 cell protection is mediated by V1 receptors. Finally, the downstream molecules of PI3K pathway were not measured in this study. An exact signal pathway may clearly interpret the protective effect of terlipressin following OGD injury.

In conclusion, the results of the current study demonstrate that, in vitro, $\mathrm{OGD} / \mathrm{R}$ attack increases the production of TNF- $\alpha$ and isoprostane, as well as the apoptosis of IEC-6 cells, and decreases cell viability and proliferation. Moreover, the current results indicate for the first time that terlipressin reduces inflammation, oxidative stress and apoptosis, and directly protects IEC- 6 cells against OGD/R-induced damage via the PI3K pathway. These important findings may help medical researchers and clinicians to better understand the pharmacological characteristics of terlipressin, and provide useful information for clinical trials and applications relevant to vasopressin.

\section{Acknowledgements}

The authors wish to express their gratitude to Ke-Xuan Liu (Department of Anesthesiology, The First Affiliated Hospital, Sun Yat-sen University) for the technical support given. The present study was supported by grants from the Natural Science Foundation of Guangdong Province, China (grant nos. 2014A030313210 and S2013010015398), and by a grant from the Major Science and Technology Projects of Guangdong province, China (grant no. 2012A080204018).

\section{References}

1. Mallick IH, Yang W, Winslet MC and Seifalian AM: Ischemia-reperfusion injury of the intestine and protective strategies against injury. Dig Dis Sci 49: 1359-1377, 2004

2. Feinman R, Deitch EA, Watkins AC, Abungu B, Colorado I, Kannan KB, Sheth SU, Caputo FJ, Lu Q, Ramanathan M, et al: HIF-1 mediates pathogenic inflammatory responses to intestinal ischemia-reperfusion injury. Am J Physiol Gastrointest Liver Physiol 299: G833-G843, 2010.

3. Martin B: Prevention of gastrointestinal complications in the critically ill patient. AACN Adv Crit Care 18: 158-166, 2007.
4. Leone M, Bechis C, Baumstarck K, Ouattara A, Collange O, Augustin P, Annane D, Arbelot C, Asehnoune K, Baldési O, et al: Outcome of acute mesenteric ischemia in the intensive care unit: A retrospective, multicenter study of 780 cases. Intensive Care Med 41: 667-676, 2015.

5. Holmes CL and Walley KR: Vasoactive drugs for vasodilatory shock in ICU. Curr Opin Crit Care 15: 398-402, 2009.

6. Dellinger RP, Levy MM, Rhodes A, Annane D, Gerlach H, Opal SM, Sevransky JE, Sprung CL, Douglas IS, Jaeschke R, et al: Surviving sepsis campaign: International guidelines for management of severe sepsis and septic shock: 2012. Crit Care Med 41: 580-637, 2013.

7. Knotzer H, Pajk W, Maier S, Ladurner R, Kleinsasser A, Wenzel V, Dünser MW, Ulmer H and Hasibeder WR: Arginine vasopressin reduces intestinal oxygen supply and mucosal tissue oxygen tension. Am J Physiol Heart Circ Physiol 289: H168-H173, 2005.

8. Maier S, Hasibeder W, Pajk W, Hengl C, Ulmer H, Hausdorfer H, Wurzinger B and Knotzer H: Arginine-vasopressin attenuates beneficial norepinephrine effect on jejunal mucosal tissue oxygenation during endotoxinaemia. Br J Anaesth 103: 691-700, 2009.

9. Nygren A, Thorén A and Ricksten SE: Vasopressin decreases intestinal mucosal perfusion: A clinical study on cardiac surgery patients in vasodilatory shock. Acta Anaesthesiol Scand 53: 581-588, 2009.

10. Qiu X, Huang Y, Xu J, Qiu H and Yang Y: Effects of terlipressin on microcirculation of small bowel mesentery in rats with endotoxic shock. J Surg Res 188: 503-509, 2014.

11. Wafa K, Lehmann C, Wagner L, Drzymulski I, Wegner A and Pavlovic D: Desmopressin improves intestinal functional capillary density and decreases leukocyte activation in experimental endotoxemia. Microvasc Res 97: 98-104, 2015.

12. Shen JT, Li YS, Xia ZQ, Wen SH, Yao X, Yang WJ, Li C and Liu KX: Remifentanil preconditioning protects the small intestine against ischemia/reperfusion injury via intestinal $\delta$ - and $\mu$-opioid receptors. Surgery 159: 548-559, 2016.

13. Milatovic D, Montine TJ and Aschner M: Measurement of isoprostanes as markers of oxidative stress. Methods Mol Biol 758: 195-204, 2011.

14. Wen SH, Li Y, Li C, Xia ZQ, Liu WF, Zhang XY, Lei WL, Huang WQ and Liu KX: Ischemic postconditioning during reperfusion attenuates intestinal injury and mucosal cell apoptosis by inhibiting JAK/STAT signaling activation. Shock 38: 411-419, 2012.

15. Zhang XY, Liu ZM, Wen SH, Li YS, Li Y, Yao X, Huang WQ and Liu KX: Dexmedetomidine administration before, but not after, ischemia attenuates intestinal injury induced by intestinal ischemia-reperfusion in rats. Anesthesiology 116: 1035-1046, 2012.

16. Chen J, Liu Y, Soh JW and Aguilera G: Antiapoptotic effects of vasopressin in the neuronal cell line $\mathrm{H} 32$ involve protein kinase Calpha and beta. J Neurocheml 10: 1310-1320, 2009.

17. Chen J, Volpi S and Aguilera G: Anti-apoptotic actions of vasopressin in $\mathrm{H} 32$ neurons involve MAP kinase transactivation and Bad phosphorylation. Exp Neurol 211: 529-538, 2008.

18. Higashiyama M, Ishikawa S, Saito T, Nakamura T, Kusaka I, Nagasaka S, Honda K and Saito T: Arginine vasopressin inhibits apoptosis of rat glomerular mesangial cells via V1a receptors. Life Sci 68: 1485-1493, 2001.

19. Ikeda H, Suzuki Y, Suzuki M, Koike M, Tamura J, Tong J, Nomura M and Itoh G: Apoptosis is a major mode of cell death caused by ischaemia and ischaemia/reperfusion injury to the rat intestinal epithelium. Gut 42: 530-537, 1998.

20. Wang G, Chen Z, Zhang F, Jing H, Xu W, Ning S, Li Z, Liu K, Yao J and Tian X: Blockade of PKC $\beta$ protects against remote organ injury induced by intestinal ischemia and reperfusion via a p66shc-mediated mitochondrial apoptotic pathway. Apoptosis 19: 1342-1353, 2014.

21. Ozacmak HS, Ozacmak VH, Barut F, Araslı M and Ucan BH: Pretreatment with mineralocorticoid receptor blocker reduces intestinal injury induced by ischemia and reperfusion: Involvement of inhibition of inflammatory response, oxidative stress, nuclear factor $\kappa \mathrm{B}$, and inducible nitric oxide synthase. J Surg Res 191: 350-361, 2014.

22. Wang WM, Liu Z, Liu AJ, Wang YX, Wang HG, An D, Heng B, Xie LH, Duan JL and Liu YQ: The zinc ion chelating agent TPEN attenuates neuronal Death/apoptosis caused by Hypoxia/ischemia via mediating the pathophysiological cascade including excitotoxicity, oxidative Stress and inflammation. CNS Neurosci Ther 21: 708-717, 2015. 
23. Liu H, Wei X, Kong L, Liu X, Cheng L, Yan S, Zhang X and Chen L: NOD2 is involved in the inflammatory response after cerebral ischemia-reperfusion injury and triggers NADPH oxidase 2-derived reactive oxygen species. Int J Biol Sci 11: $525-535,2015$.

24. Zhang YJ, Zhang AQ, Zhao XX, Tian ZL and Yao L: Nicorandil protects against ischaemia-reperfusion injury in newborn rat kidney. Pharmacology 92: 245-256, 2013.

25. Li J, Zhou J, Zhang D, Song Y, She J and Bai C: Bone marrow-derived mesenchymal stem cells enhance autophagy via PI3K/AKT signalling to reduce the severity of ischaemia/reperfusion-induced lung injury. J Cell Mol Med 19: 2341-2351, 2015.

26. Ferrier L, Serradeil-Le Gal C, Schulte AM, Vasina V, Gaultier E, Schroedel S, Ursino MG, Chaumaz G, Pascal M, De Ponti F and Bueno L: Proinflammatory role of vasopressin through V1b receptors in hapten-induced experimental colitis in rodents: Implication in IBD. Am J Physiol Gastrointest Liver Physiol 299: G1298-G1307, 2010.

27. Boyd JH, Holmes CL, Wang Y, Roberts H and Walley KR: Vasopressin decreases sepsis-induced pulmonary inflammation through the V2R. Resuscitation 79: 325-331, 2008.

28. Maybauer MO, Maybauer DM, Enkhbaatar P, Laporte R, Wiśniewska H, Traber LD, Lin C, Fan J, Hawkins HK, Cox RA, et al: The selective vasopressin type la receptor agonist selepressin (FE 202158) blocks vascular leak in ovine severe sepsis*. Crit Care Med 42: e525-e533, 2014.
29. Nazari A, Sadr SS, Faghihi M, Azizi Y, Hosseini MJ, Mobarra N, Tavakoli A and Imani A: Vasopressin attenuates ischemia-reperfusion injury via reduction of oxidative stress and inhibition of mitochondrial permeability transition pore opening in rat hearts. Eur J Pharmacol 760: 96-102, 2015.

30. Nakatani Y, Chin Y, Hara S and Kudo I: Immediate prostaglandin E2 synthesis in rat 3Y1 fibroblasts following vasopressin V1a receptor stimulation. Biochem Biophys Res Commun 354: 676-680, 2007.

31. Miller RL, Sandoval PC, Pisitkun T, Knepper MA and Hoffert JD: Vasopressin inhibits apoptosis in renal collecting duct cells. Am J Physiol Renal Physiol 304: F177-F188, 2013.

32. Zhang W, Xing B, Yang L, Shi J and Zhou X: Icaritin attenuates myocardial ischemia and reperfusion injury via anti-inflammatory and anti-oxidative stress effects in rats. Am J Chin Med 43: 1083-1097, 2015.

33. Zhang Y, Tian SY, Li YW, Zhang L, Yu JB, Li J, Chen YY, Wang YX, Liang Y, Zhang XS, et al: Sevoflurane preconditioning improving cerebral focal ischemia-reperfusion damage in a rat model via PI3K/Akt signaling pathway. Gene 569: 60-65, 2015.

34. Liu X, Zhang C, Qian L, Zhang C, Wu K, Yang C, Yan D, Wu X and Shi J: NF45 inhibits cardiomyocyte apoptosis following myocardial ischemia-reperfusion injury. Pathol Res Pract 211: 955-962, 2015 